\title{
Motility studies in diverticular disease of the colon
}

\author{
T. G. PARKS AND A. M. CONNELL \\ From the Department of Surgery, Queen's University of Belfast
}

\section{Part I Basal activity and response to food assessed by open-ended tube and miniature balloon techniques}

Arfwidsson (1964) showed that the activity of the sigmoid colon in diverticular disease was greater than normal under resting conditions, following a meal, and after an injection of prostigmine, and he postulated that the muscle in diverticular disease was generally overactive. In the same year Painter and Truelove (1964) found that patients with diverticular disease did not differ from normal under resting conditions but that segments of the colon containing diverticula reacted in an excessive way to pharmacological stimuli such as prostigmine and morphine. They wondered if naturally occurring stimuli also evoke an exaggerated response causing herniation of colonic mucosa.

While these authors reach a similar hypothesis about the aetiology of diverticular disease, their reports differ materially and so, using the open tube technique, we have studied intraluminal pressures in the sigmoid colon and rectum in patients with diverticular disease.

We have considered the motility not only under resting conditions but also the response to the physiological stimulus of eating, as any hypothesis about the aetiology of diverticular disease must be related to a repetitive physiological stimulus such as eating rather than pharmacological stimuli which occur only rarely in the life of the individual.

In addition, observations were made on another group of patients and controls, using miniature balloons, to assess whether differences detected by the open tube could be confirmed by an alternative method of pressure recording.

\section{STUDIES USING OPEN-ENDED TUBE TECHNIQUE}

APPARATUS EMPLOYED Three polythene tubes of $2 \mathrm{~mm}$ internal diameter were assembled side by side so that their ends were $7 \cdot 5 \mathrm{~cm}$ apart. In addition to each tube having an open-ended tip, two small side holes were made near to the end to reduce the liability of the lumen to blockage by faecal material or mucosa of the bowel. Each of the three open-ended tubes was connected to a pressure transducer recording on a multichannel electromanometer (Schwartzer-München). The tubes were filled with water before the recording and during the experiment a slow stream of water was continually infused at a rate of $7 \mathrm{ml}$ per hour.

PROCEDURE The tubes, which were closely bound, were inserted through a sigmoidoscope and, where possible, the recording tips were placed at $25,17.5$, and $10 \mathrm{~cm}$ from the anus.

After introduction of the tubes, the patient lay comfortably in the supine position with the head slightly elevated. A stethograph applied to the abdomen was used to record respiratory and somatic movements. A period of approximately 15 minutes was allowed to elapse before recording was started.

PATIENTS STUDIED Tracings were obtained from 36 patients with diverticular disease of the colon. All patients had previously had a barium enema and only patients who had diverticula in the lower sigmoid colon were selected. In 22 cases it was possible to insert the tubes so that the upper tip lay in the sigmoid colon $(25 \mathrm{~cm}$ from the anus) and the lowest tip lay in the upper rectum.

For comparison, studies were carried out on 18 subjects who suffered from first degree haemorrhoids. None of these had clinical, sigmoidoscopic, or radiological evidence of colonic disease.

Tracings were obtained from all patients during a 30-minute period under basal conditions. A standard lunch was given to 24 patients with diverticular disease and to 11 of the control subjects, and recording was continued for at least 30 minutes after the meal.

ANALYSIS OF RECORDS In a number of records, one or other of the tracings was deemed to be distorted, probably due to blockage of the recording tube, and analyses have been carried out only on those records which were technically satisfactory.

During the basal and after-lunch periods the following fardmeters were measured and have been used to express the activity: (1) the percentage of time during which activity occurred; (2) the mean amplitude of the principal waves in $\mathrm{cm} \mathrm{H}_{2} \mathrm{O}$; (3) the product of 1 and 2 , ie, the percentage duration of activity $\times$ mean amplitude, 


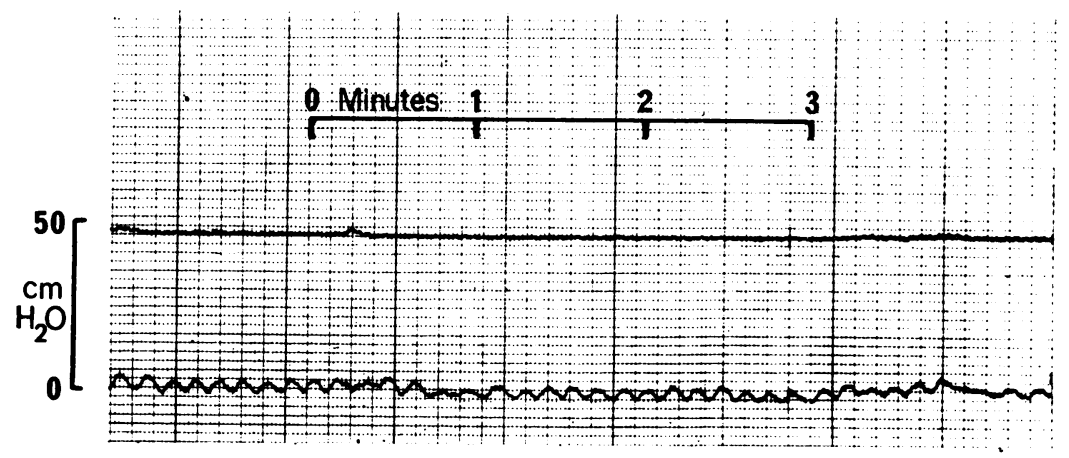

FIG. 1. Recording from a patient with diverticular disease showing continence waves in the rectum. which gives an index of the total activity; (4) the total number of waves in the 30 -minute period; (5) the number of waves of more than one-minute duration in the 30minute period; (6) the number of fast wave complexes in the 30-minute period; and (7) the percentage of the time of analysis occupied by continence waves (Fig. 1), which are simple waves occurring regularly at a rate of six to 10 per minute.

RESULTS The results of analyses of basal activity in the control subjects and in patients with diverticular disease are set out in Table I.

Basal conditions In the sigmoid colon of the diseased patients the total activity detected as expressed by the product was 224 compared with
159 in the control group. The strength of the contractions was greater in diverticular disease.

At rectosigmoid level the motility detected was almost identical in the two groups.

There is a suggestion that there was less activity in the rectum of patients with diverticular disease than in the controls. The total activity was 107.7 in patients with diverticular disease and 142.7 in the control series. The duration of activity was slightly less but the strength of contractions slightly greater in the diseased group. These differences, however, could have occurred by chance.

Wave form during basal recording The most common type of wave seen in health and in diver-

TABLE I

BASAL ACTIVITY DETECTED IN PATIENTS WITH DIVERTICULAR DISEASE AND IN CONTROL SUBJECTS RECORDED BY THE OPEN-TUBE METHOD

\begin{tabular}{|c|c|c|c|c|c|c|}
\hline & \multicolumn{3}{|c|}{ Control Subjects } & \multicolumn{3}{|c|}{ Diverticular Disease } \\
\hline & $\begin{array}{l}\text { Sigmoid } \\
\text { (12 Analyses) }\end{array}$ & $\begin{array}{l}\text { Recto- } \\
\text { sigmoid } \\
\text { (14 Analyses) }\end{array}$ & $\begin{array}{l}\text { Rectum } \\
\text { (15 Analyses) }\end{array}$ & $\begin{array}{l}\text { Sigmoid } \\
\text { (17 Analyses) }\end{array}$ & $\begin{array}{l}\text { Recto- } \\
\text { sigmoid } \\
(27 \text { Analyses })\end{array}$ & $\begin{array}{l}\text { Rectum } \\
\text { (28 Analyses) }\end{array}$ \\
\hline $\begin{array}{l}\text { Duration of activity }(\%) \\
\text { Mean amplitude }\left(\mathrm{cm} \mathrm{H}_{2} \mathrm{O}\right) \\
\text { Product }\end{array}$ & $\begin{array}{r}18 \cdot 6 \\
7 \cdot 7 \\
15 \% \cdot 0\end{array}$ & $\begin{array}{r}22 \cdot 4 \\
7 \cdot 6 \\
218 \cdot 8\end{array}$ & $\begin{array}{r}21 \cdot 0 \\
4 \cdot 9 \\
142 \cdot 7\end{array}$ & $\begin{array}{r}18 \cdot 0 \\
10 \cdot 4 \\
224 \cdot 0\end{array}$ & $\begin{array}{r}20 \cdot 5 \\
8 \cdot 4 \\
191 \cdot 6\end{array}$ & $\begin{array}{r}16 \cdot 9 \\
6 \cdot 3 \\
107 \cdot 7\end{array}$ \\
\hline
\end{tabular}

TABLE II

INCIDENCE OF WAVES DETECTED DURING 30 MINUTES OF BASAL RECORDING

Control Subjects Diverticular Disease

\begin{tabular}{lllllll}
\hline & Recto- & & & & Recto- & \\
Sigmoid & sigmoid & Rectum & & Sigmoid & sigmoid & Rectum \\
$(19$ Analyses $)$ & $(14$ Analyses $)$ & $(15$ Analyses $)$ & & $(17$ Analyses $)$ & $(27$ Analyses $)$ & $(28$ Analyses $)$ \\
\hline
\end{tabular}

Total number of simple waves per $30 \mathrm{~min}$

Number of waves of more

than 1 min duration

Number of fast wave

complexes

$12 \cdot 3$

Time occupied by

continence waves $(\%)$

$\begin{array}{ll}12 \cdot 3 & 12 \cdot 1 \\ 1 \cdot 07 & 0 \cdot 79 \\ 0 \cdot 10 & 0.4 \\ 0 & 0\end{array}$

$12 \cdot 5$
0.93
0.21
$2 \cdot 5$

$11 \cdot 8$
$1 \cdot 25$
$0 \cdot 88$
0

$12 \cdot 2$

$10 \cdot 34$

$1 \cdot 35$

0.73

$1 \cdot 26$

0.3

$1 \cdot 58$

$2 \cdot 85$ 
TABLE III

EFFECT OF EATING ON MOTOR ACTIVITY IN SIGMOID IN CONTROL SUBJECTS RECORDED BY THE OPEN-TUBE METHOD

\begin{tabular}{|c|c|c|c|c|c|c|}
\hline & \multicolumn{2}{|c|}{$\begin{array}{l}\text { Sigmoid } \\
\text { (7 Analyses) }\end{array}$} & \multicolumn{2}{|c|}{$\begin{array}{l}\text { Rectosigmoid } \\
\text { (7 Analyses) }\end{array}$} & \multicolumn{2}{|c|}{$\begin{array}{l}\text { Rectum } \\
(8 \text { Analyses })\end{array}$} \\
\hline & Resting & Postprandial & Resting & Postprandial & Resting & Postprandial \\
\hline Duration of activity $(\%)$ & $22 \cdot 2$ & $18 \cdot 7$ & $25 \cdot 3$ & $25 \cdot 9$ & $21 \cdot 8$ & $21 \cdot 1$ \\
\hline Mean amplitude $\left(\mathrm{cmH}_{2} \mathrm{O}\right)$ & $5 \cdot 2$ & $8 \cdot 7$ & $7 \cdot 3$ & $8 \cdot 7$ & $4 \cdot 4$ & $6 \cdot 1$ \\
\hline Product & 146 & 222 & 201 & 264 & 137 & 162 \\
\hline $\begin{array}{l}\text { Effect of lunch (\% increase } \\
\text { in activity) }\end{array}$ & \multicolumn{2}{|c|}{$52 \%$} & \multicolumn{2}{|c|}{$32 \%$} & \multicolumn{2}{|c|}{$18 \%$} \\
\hline
\end{tabular}

TABLE IV

EFFECT OF EATING ON MOTOR ACTIVITY IN SIGMOID IN PATIENTS WITH DIVERTICULAR DISEASE RECORDED BY THE OPEN-TUBE METHOD

\begin{tabular}{|c|c|c|c|c|c|c|}
\hline & \multicolumn{2}{|c|}{$\begin{array}{l}\text { Sigmoid } \\
\text { (14 Analyses) }\end{array}$} & \multicolumn{2}{|c|}{$\begin{array}{l}\text { Rectosigmoid } \\
\text { (10 Analyses) }\end{array}$} & \multicolumn{2}{|c|}{$\begin{array}{l}\text { Rectum } \\
\text { (I8 Analyses) }\end{array}$} \\
\hline & Resting & Postprandial & Resting & Postprandial & Resting & Postprandial \\
\hline $\begin{array}{l}\text { Duration of activity }(\%) \\
\text { Mean amplitude }\left(\mathrm{cm} \mathrm{H}_{2} \mathrm{O}\right) \\
\text { Product } \\
\text { Effect of Innch ( } \% \text { increase } \\
\text { in activity) }\end{array}$ & $\begin{array}{r}18 \cdot 1 \\
8 \cdot 1 \\
170\end{array}$ & $\begin{array}{c}29 \cdot 9 \\
16 \cdot 1 \\
447\end{array}$ & $\begin{array}{r}20 \cdot 6 \\
8 \cdot 1 \\
182\end{array}$ & $\begin{array}{r}24 \cdot 7 \\
10 \cdot 0 \\
266\end{array}$ & $\begin{array}{l}13 \cdot 9 \\
6 \cdot 4 \\
98\end{array}$ & $\begin{array}{r}21 \cdot 4 \\
8 \cdot 4 \\
199\end{array}$ \\
\hline
\end{tabular}

ticular disease, under resting conditions, was the simple principal wave. Table II summarizes the average number of waves occurring in the 30-minute basal period and the incidence of various types.

In the sigmoid the average number of waves recorded in the 30-minute basal period was 11.8 in patients with diverticular disease and 12.3 in the control subjects. In the diseased sigmoid, waves of more than one-minute duration and also fast wave complexes were recorded more often than in health. This tendency to prolonged waves and to fast wave complexes was also seen at the rectosigmoid level.

The wave forms in the rectum were similar in the two groups. Continence waves, which were not seen in the sigmoid during the resting phase, occurred in the rectum of diverticular and control subjects with equal frequency (Fig. 1).

Response to physiological stimulus of eating The effect of eating on the motor activity of those patients with diverticular disease and control subjects for whom analyses are available is set out in Tables III and IV.

In the control series, eating resulted in an increase in total motor activity of approximately $52 \%$ in the sigmoid and $32 \%$ at the rectosigmoid, and $18 \%$ in the rectum.

In diverticular disease, the duration of activity and the amplitude of the waves increased markedly in the postprandial period, particularly in the sigmoid area so that the increase in total activity here was more than $153 \%$ of the original value. The increase in activity at the rectosigmoid and rectum was less marked.
Wave form during period after lunch In the control series, eating resulted in only minor differences in the total number of waves and the incidence of various wave forms. In patients with diverticular disease eating resulted in an increased incidence of prolonged waves (more than one minute) and a greater total number of waves recorded in the 30-minute period after lunch.

\section{STUDIES USING MINIATURE BALLOON TECHNIQUE}

METHODS Intraluminal pressures were recorded using miniature balloons connected via fine polythene tubing either to an optical manometer recording on photographic paper (Rowlands, Honour, Edwards, and Corbett, 1953) or to an electromanometer and direct writing system. Otherwise the procedure for recording and analysis of recording was exactly as in the openended tube study.

PATIENTS Motility was assessed in 25 patients with diverticular disease of the colon, the lower sigmoid being involved in every case. Studies were carried out on 15 control subjects with asymptomatic duodenal ulcer and four with first degree haemorrhoids. None had clinical evidence of colonic disease nor any symptoms referable to the colon at the time of study.

RESULTS Results of analyses for patients with diverticular disease and control subjects are set out in Table $\mathrm{V}$.

Basal conditions In both groups under resting conditions simple waves representing segmental contractions again predominated, with periods of activity alternating with periods of quiescence. The 
TABLE V

MOTILITY IN SIGMOID COLON AND UPPER RECTUM RECORDED BY MINIATURE BALLOON METHOD

\begin{tabular}{lllll}
$\begin{array}{l}\text { Sigmoid Colon } \\
(25 \mathrm{~cm} \text { from anus })\end{array}$ & & \multicolumn{2}{l}{$\begin{array}{l}\text { Upper Rectum } \\
(15 \mathrm{~cm} \text { from } \text { anus })\end{array}$} \\
\cline { 1 - 1 } $\begin{array}{l}\text { Control } \\
\text { Subjects }\end{array}$ & $\begin{array}{l}\text { Diverti- } \\
\text { cular } \\
\text { Disease }\end{array}$ & & $\begin{array}{l}\text { Control } \\
\text { Subjects }\end{array}$ & $\begin{array}{l}\text { Diverti- } \\
\text { cular } \\
\text { Disease }\end{array}$
\end{tabular}

\begin{tabular}{lrrrr}
\hline Basal & & & & \\
$\begin{array}{l}\text { Duration of activity } \\
\text { Mean amplitude }\end{array}$ & 45.8 & 26.7 & 34.1 & 22.36 \\
$\begin{array}{l}\text { Product } \\
\text { After lunch }\end{array}$ & 528.3 & 470.4 & 250.6 & 330.0 \\
$\begin{array}{l}\text { Duration of activity } \\
\text { Mean amplitude }\end{array}$ & $55 \cdot 2$ & 39.6 & 40.5 & 29.8 \\
$\begin{array}{l}\text { Product } \\
\text { Effect of lunch (\% }\end{array}$ & 926.7 & 819.5 & 335.2 & 399.6 \\
increase in activity) & 75 & 74 & 33 & 21
\end{tabular}

duration of activity in patients with diverticular disease $(26.7 \%)$ was less than that of the controls $(45.8 \%)$. The duration of activity of the rectum was also less in the diverticular group (Table V). On the other hand, the amplitude of the waves was higher in the sigmoid and rectum of the diverticular patients, making the total activity similar to that of the controls.

Response to physiological stimulus of eating In the diverticular group, eating resulted in an increase in activity of $74 \%$ over the resting level in the sigmoid colon which is a very similar increase to that following eating within control patients $(75 \%)$. Again, the amplitude of the recorded waves was greater in both the sigmoid and rectum of diseased patients.

\section{COMPARISON OF THE RESULTS USING DIFFERENT METHODS}

Using open tubes, only slightly more colonic activity than normal was detected in patients with diverticular disease under resting conditions, but using miniature balloons as the method of recording, patients with diverticular disease appeared to have less activity than control subjects.

Using open tubes, the relative increase in motility after eating in patients with diverticular disease appeared to be much greater than that in normal subjects giving the impression of an exaggerated response. However, using miniature balloons the relative increase in motility after eating in patients with diverticular disease was the same as in the control subjects.

\section{DISCUSSION}

Our observations by the open-tube method appear to indicate an exaggerated colonic-motility response to food in diseased patients.
The detection of increased motor activity of the diverticular segment and its exaggerated response to food might reasonably be recorded as an expression of hyperexcitability. But these conclusions must be presented cautiously because intraluminal pressures are caused not only by wall movements but also by the ease with which pressure segments are formed. This implicates factors such as mucosal exuberance, the nature of the bowel content, and the diameter of the lumen.

Using the miniature balloon technique it was not possible to demonstrate overall hypermotility, and the response to food detected by this method was no greater in diverticular disease than normal, although the amplitude of the waves was greater.

The explanation for the difference in the results of the two parts of the study must lie in the nature of the recording device. Figure 2 represents four possible situations. An open-ended tube will detect pressure only if pressure segments are formed. In an organ with a wide lumen (A), there may be considerable activity in the wall of the bowel without effecting any detectable change in intraluminal pressure. A miniature balloon, however, is more likely to be in contact with the wall (B) and thus able to detect a higher proportion of the wall activity. Where, however, the lumen is narrow, the possibility of pressure segments being formed is greater, so that an open tube (C) may detect a higher proportion of wall activity than would occur if the lumen were wide. The miniature balloon is still in a favourable position to detect wall activity (D). Thus, the change from wide to narrow lumen will result in a greater increase in the amount of activity recorded by the open tube than that recorded by the miniature balloon. Such a change in luminal diameter can occur after eating. It is possible that the greater response after eating recorded in diverticular pa-

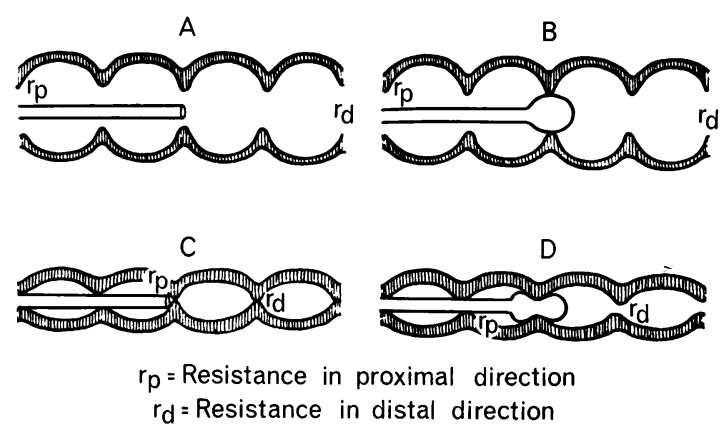

FIG. 2. Diagrammatic representation of the effects of colonic contractions on a miniature balloon and on an openended tube. 
tients by the open-ended tube method reflects more the narrowed segment from which recording is made rather than any absolute increase in wall activity. It is possible that the exaggerated activity recorded by Painter and Truelove (1964) in patients with diverticular disease stimulated by morphia or prostigmine could be explained on the same basis. The higher intraluminal pressures occurring in the diverticular patients may contribute to the production of pulsion diverticula but the present findings would indicate that these pressures develop in a previously narrowed segment of bowel. Whether this narrowing exists before the diverticula appear cannot be determined on the evidence of this study. However, many cases are on record of diverticular disease with narrowing but no diverticula (Morson, 1963; Parks, 1966; Williams, 1967) so it seems possible that the muscular contracture is the primary lesion.

\section{SUMMARY}

The overall activity recorded using miniature balloons was similar in diverticular disease and in health under basal conditions and after the physiological stimulus of eating. The duration of activity was less but the amplitude of the waves was greater in diseased subjects.

Open-ended tubes detected more basal and postprandial activity in diverticular disease than normal, but this does not necessarily indicate true muscular hyperactivity.

Intraluminal pressures are determined not only by wall movements, but the ease with which pressure segments are formed, and this implicates factors such as the diameter of the lumen, mucosal exuberance, and the nature of the bowel content.

\section{REFERENCES}

Arfwidsson, S. (1964). Pathogenesis of multiple diverticula of the sigmoid colon in diverticular disease. Acta. chir. Scand., Suppl. 342.

Morson, B. C. (1963). The muscle abnormality in diverticular disease of the sigmoid colon. Brit. J. Radiol., 36, 385-392.

Parks, T. G. (1966). An inquiry into the pathogenesis of diverticular disease of the colon. M.Ch. Thesis, Belfast.

Williams, I. (1967). Diverticular disease of the colon without divert icula. Radiology, 89, 401-412.

Painter, N. S., and Truelove, S. C. (1964). The intraluminal pressure patterns in diverticulosis of the colon. Gut, 5, 201-213, 365-373.

Rowlands, E. N., Honour, A. J., Edwards, D. A. W., and Corbett, B. D. (1953). Metal-capsule optical manometer for measuring pressure in the human gut with an open-ended tube. Clin. Sci., 12, 299-306.

\section{Part II Effect of colonic and rectal distension}

The muscle of the sigmoid in diverticular disease is frequently thickened and rigid (Morson, 1963). It seemed likely, therefore, that its response to a stretching force might differ from normal. The resistance of colonic muscle to a stretching force has been little studied and the present work compares the response to stretch of muscle in diverticular disease and controls.

\section{METHODS}

Large balloons made from soft rubber with their centres $7.5 \mathrm{~cm}$ apart were connected via polythene tubing to both a water manometer and a multichannel electromanometer (Schwartzer-München). A side arm into the system allowed the introduction of fluid. Three polythene tubes of $2 \mathrm{~mm}$ internal diameter with their tips $7.5 \mathrm{~cm}$ apart were used to assess intraluminal pressure changes (Fig. 1).

Studies were attempted on 28 patients with diverticular disease and 15 control subjects with first degree haemorrhoids. Where possible, the recording tips of the openended tubes were placed at $25,17.5$, and $10 \mathrm{~cm}$ from the anus, but in 12 cases of diverticular disease and in three controls it was not possible to pass the tubes beyond the rectosigmoid junction. In these cases only the effects of rectal distension could be observed. Thus

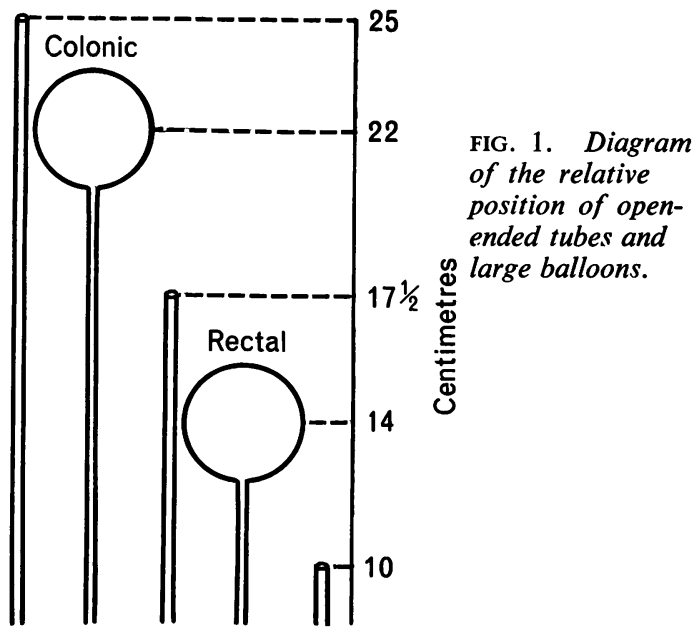

